whatever occupation he may choose to follow. That if he continues in school he may make the more rapid progress not only because of his knowledge of the general laws of matter and energy but also because of a more rational attitude toward knowledge. Therefore that the course may in the highest degree possible have served the purpose of education-the removal of limitations.

\title{
WHAT THE COLLEGE DESIRES OF THE HIGH SCHOOL IN THE TEACHING OF PHYSICAL GEOGRAPHY.
}

\author{
By T. C. Hopkins, \\ Syracuse University.
}

The subject assigned me was what the college requires of the high school. In my opinion there is only one answer to this question, namely, nothing. The college does not and should not make any requirements of the high school. The college does require a certain amount of preliminary training of students desiring to take up and carry on the college studies. The prospective college student is expected to show that somewhere, in some way, he has had sufficient preparation to carry on the work given in the college courses. He may get this in the high school or he may get it somewhere else. Since but a small fraction of the high school students go to college the fitting of pupils for college should be a minor factor in the work of the high school.

Is the object of the work in the high school the same as that in the college or is it different? Is it the education (the drawing out or development of the intellect) of the pupil or is it something different? Are these two schools part of a great educational system or are they something radically different? What does the college attempt to do that is not attempted in a more elementary way in the high school and vice versa? If one of these schools has a mission to perform different from the other then let it by all means stick to that mission. If they are both trying to develop the intellect and character of the youth so that they will be wiser, better, and stronger citizens then why should there be any conflict between the two unless perchance it may be as to where the one leaves off and the other begins?

Now as to physiography: let us see what the college expects or desires of the entering student and whether there is anything therein out of harmony with the high school ideals, should the student want to get this preliminary training in the high school. 
The college does not require any student to study physical geography in the high school or any other school in order to enter the college courses. (There may possibly be some exceptions to this but I do not know of any.) It asks the pupil to have had a certain number of hours or years of study along different lines of knowledge; one of these lines may be (not must be) physiography. If he chooses physiography as one of these lines of preparation then in New York State it expects him to have done a year's work of five periods a week in that subject and further that not less than one fifth of this work should be of a practical character, commonly designated laboratory work, part of which should be the study of physiographic features and agencies in field trips. No specific requirements are made in this line; both the quantity and kind of field work will depend on the location of the school, the size of the classes and particularly the training and energy of the teacher.

The laboratory indoors will likewise from necessity vary greatly in the kind of work done; the condition being that it be made as practical as possible and involve the study of real things. The dictation of notes by a teacher, the copying of a description of an experiment, or the copying of a diagram is not laboratory work. It means work actually done by the student involving observation of things, handling of instruments, study of rocks or minerals or maps or models, not someone else's description of them. This work should be done under the supervision of the teacher and the results recorded in a notebook. The value of the notebook is in the making of it.

Is there anything in such a course inimical to any high school ideal? If so, is there not something wrong with the ideal?

The subject of physiography as now taught in the schools is a broad one and includes several somewhat diversified lines of study. It is not possible nor is it indeed desirable that all of these divisions should be treated exhaustively nor is it necessary that they should all be mentioned even. It is more important that one or more of the branches should be taken up with some degree of thoroughness in order that the student should get the spirit and something of the methods of scientific work.

The tendency in too many schools is to make the work too superficial and mechanical, with the idea of conning all the topics and memorizing enough to answer questions in a certain catechism. It may (or it may not) be necessary for the pupil to know something of the movements of the earth and the results 
produced; of the relation of the earth to the other heavenly bodies; something of the work of the atmosphere and the water on and under the earth; the land forms; the rocks and minerals composing the earth; the kinds of animals and plants and their distribution, but if in getting this varied knowledge he fails to realize that he is actually studying or can study the book of nature, that he actually sees the omnipotent forces and agencies at work and the effects produced by them in the making of the world in which he lives and forms a part: if he fails in this he fails in the most important part of the work, and he should omit some of the topics and spend more time in the contemplation of others.

From the standpoint of the college, or from any other rational standpoint, it were better for the pupils to have a good live knowledge of one or two of the topics than a superficial word knowledge of all of them. By good knowledge I mean that he gets into the heart of the subject and sees its relation to him and his daily life and a desire to further pursue the subject. It is only the superficial pupil that "knows it all." Many of the poorest students in the college classes in physiography are those who have made a high grade in the subject in high school. He has a superficial knowledge of the subject that causes him to hold his head so high that he cannot see the earth on which he walks. He gets a memory knowledge of the nomenclature with the idea that he has the subject-matter. He can give a definition of latitude and longitude but cannot tell the difference between them on the map. To him they are "imaginary lines" without use or significance. He can define a contour map but cannot use one. Spending too much time conning text-book definitions is one reason for such a condition and a probable remedy is more laboratory and field work. Another remedy is to have trained teachers; too frequently persons are required to teach physiography who know little or nothing about it and from necessity slavishly follow the text-book and miss the inspiration of the subject.

\section{VERTICAL WRITING SCORES IN MILWAUKEE.}

By a vote of six to four the Milwaukee school board refused to change from the vertical to the slant system of writing in the public schools. The change had been recommended by a majority of a committee appointed to investigate the subject. 